\title{
Different expressions of the same mode: a recent dialogue between archaeological and contemporary drawing practices
}

\author{
Stefan Gant (1) and Paul Reilly (2*)
}

(1) Senior Lecturer in Drawing \& New Media, Department of Fine Art, Faculty of Art, Science and Technology, University of Northampton, Avenue Campus, St George's Avenue, Northampton, NN2 6JD email: stefan.gant@northampton.ac.uk. Tel: 01604 893150

(2) * Corresponding author. Visiting Senior Research Fellow, Faculty of Humanities, University of Southampton, Avenue Campus, Highfield, Southampton, SO17 1BF, UK. Tel: 01794 341961. Email: p.reilly@soton.ac.uk. ORCID: orcid.org/0000-00028067-8991

Stefan Gant's practice and research explores the discourse of contemporary drawing. Through peer selection, Gant was selected as a finalist and exhibitor in 2007, 2010 and 2012 for the Jerwood Drawing Prize, London and UK tour. He was also 'Highly Commended' at the National Eisteddfod of Wales Visual Arts Exhibition in 2007. Through his art practice, Gant challenges the notions of what drawing can be through the temporality of filmic medium and digital technologies. He has exhibited nationally and internationally and has been the recipient of Arts Council of Wales and Wales Arts International funding.

Paul Reilly is a both a practicing field archaeologist and a pioneer of virtual and creative digital archaeologies. His current research explores ontological transformations that occur when (im)material archaeology enters the digital. He has published widely (see orcid.org/0000-0002-8067-8991). Reilly is honorary life member and former chairman of the Computer Applications and Archaeology organisation (CAA), and also chairs the CAA International Scientific Committee. 


\begin{abstract}
In this article we explore what we perceive as pertinent features of shared experience at the excavations of an Iron Age Hillfort at Bodfari, North Wales, referencing artist, archaeologist and examples of seminal art works and archaeological records resulting through interdisciplinary collaboration. We explore ways along which archaeological and artistic practices of improvisation become entangled and productive through their different modes of markmaking. We contend that marks and memories of artist and archaeologist alike emerge interactively, through the mutually constituting effects of the object of study, the tools of exploration, and the practitioners themselves, when they are enmeshed in the cross-modally bound activities. These include, but are not limited to, remote sensing, surveying, mattocking, trowelling, drawing, photographing, videoing and sound recording. These marks represent the co-signatories: the gesture of the often anonymous practitioners, the voice of the deposits, as well as the imprint of the tools, and their interplay creates a multi-threaded narrative documenting their modes of intra-action, in short our practices. They occupy the conceptual space of paradata, and in the process of saturating the interstices of digital cognitive prosthetics they lend probity to their translations in both art form and archive.
\end{abstract}




\section{Introduction}

Intersecting archaeological and artistic practices in cultural production, and their mutually fruitful engagement with the material and how they each represent the world, are increasingly the subject of critical appraisal (e.g. Renfrew 2003; Renfrew, Gosden and DeMarrais 2004; Beale et al. 2013; Russell and Cochrane 2014; Chittock and Valdez-Tullett 2017; Ferraby 2017; Smith 2017). Our point of departure is taken from philosopher Matthew Crawford's stimulating book, The World Beyond Your Head: How to Flourish in an Age of Distraction, in which he argues convincingly for the importance of fostering 'ecologies of attention'; the skill of paying attention to what is important. Such ecologies of skilled perception are developed through processes of mentoring and deep sensory immersion, the product of repeated physical interactions in the chosen endeavour. In such environments pragmatism surpasses epistemological purity. Crawford demonstrates that it is by doing that the perceptions of a skilled practitioner become tuned to certain features and aspects of their working environment, that is the objects of attention and the affordances of the tools and materials that are pertinent to effective action. In short, Crawford asserts that the robust and demanding skills developed through embodied experience, or action, not only underpin but enhance the practitioner's comprehension of their world (Crawford 2015).

Field archaeologists and fine artists are examples of practitioners who develop their practices in such ecologies (see Edgeworth 2013; Graves-Brown 2013; Smith 2017). Their practices, however, are dissimilar and can have productive affinities when they jointly engage and cause each practice to refract through the work of the other. Our contrasting methodologies become conversations, not debates, in which the interlocutors become at once interdependent apprentices, journeymen and masters. To participate in these conversations requires all participants to develop new powers of expression and to foster communal learning about our joint objects of attention. This is our aspiration at the on-going excavations of an Iron Age hillfort at Moel-y-Gaer, Bodfari, in North Wales (see Lock and Pouncett 2012; 2014; in prep.).

We argue that pertinent features of the shared space of the Bodfari investigations become objects of joint focus, and thus a shared vehicle for communication, mutual intelligibility, and enhanced insights as both artist and archaeologist apprehend them through sensorimotor engagement. We further assert that when our two modes of practice interact, cross-modal cognitive finessing develops in both sets of practitioners; our senses sharpened as they become more sensitised to new, jointly relevant, considerations. The objects of our shared interests become generative of new physical and theoretical affordances and the locus of creative engagement and genuine agency.

In this article, we explore ways along which archaeological and artistic practices of improvisation become entangled and productive through their different modes of apprehending the world using distinct practices of mark-making. The Bodfari project has utilised a wide range of digital recording approaches to mitigate the low yield of diagnostic archaeological artefacts. This factor has resulted in a greater alignment between artist and archaeologist who both employ many different ways to approach this ancient buried landscape. This article then results from a multi-threaded conversation, spanning over more than four years of increasing interaction, and underpinned by cross-modal, interdisciplinary engagement. These extended approaches of looking at, reading and analysing buried 
landscapes involving both archaeologist and artist have generated shared experiential insights and a growing awareness of our different internalised habits of perception, enquiry and modes of learning. Through such meta-learning or meta-perception (Laing, Phillipson and Lee 1966; Biggs 1985; Birgerstam 2002) our approaches have become increasingly transferable. Additionally, self-identity is heightened in the cross-correlation of shared ideas and modes of thinking in the search to get at the truth of things. This article therefore provides an opportunity to be reflexive, and disseminate and discuss our realisations to date.

We begin with a brief overview of our shared space of fieldwork at Moel-y-Gaer, Bodfari. We then introduce the artistic-archaeological dialogue we have been engaged in for the last five years, and share and discuss some of the outputs of this extended conversation. We conclude with some reflexive remarks about the nature of the archaeological record and extended drawing practices.

\section{The Shared Space of Moel-y-Gaer, Bodfari}

Moel-y-Gaer is a relatively small (c.2 hectares) irregular-shaped, multivallate, Middle Iron Age hillfort on a locally prominent hill located on the northern end of the Clwydian Range, above the village of Bodfari in Denbighshire, Wales, UK. The hillfort was first subject to inconclusive antiquarian investigations in 1908 (Stapleton 1909) The present programme of fieldwork is much broader and includes a reinvestigation of Stapleton's work. An in-depth programme of non-destructive investigations (including Lidar, micro-topographic, GPS, magnetometer, and resistivity surveys) was conducted to inform any new excavations (Lock and Pouncett 2012). Through this series of interventions the fieldworkers involved have developed a very intimate relationship with both surface details and subsurface anomalies on Moel-y-Gaer. Six trenches have been opened since 2012. Most of the insights discussed here refer to Trench $3 X$, a $25 \mathrm{~m}$ long by $5 \mathrm{~m}$ wide trench cutting through the middle rampart and its outer rock-cut ditch (Lock and Pouncett 2014). This very steep, sloping trench was overlooked on either side by pine woods, emphasising the negative space created by the excavation (figure 1), which was, eventually, in places around two-and-a-half metres deep and required some shuttering. The height of the rampart was later attenuated by the bank of turf we maintained there to help reinstate the site when we had finished our investigations. The team's findings are reported in detail elsewhere (Lock and Pouncett 2014; in prep.). However, we can state that several phases of dry-stone revetted rampart with rubble core and a deep v-shaped rock-cut outer ditch were disclosed. This shared archaeological space of our joint attention was a very stimulating place.

The rest of this paper explores how our different modes of mark-making to probe, record and represent this former shared space generated some surprising new, but complementary, insights into our different ways of knowing and our contrasting modes of doing. We begin by outlining our standard archaeological drawing procedures and then begin to extend the definition and scope of both archaeological and contemporary drawing practices.

\section{Drawing on Moel-y-Gaer, Bodfari}

Drawing has a long association with archaeology and its forebearers such as antiquarianism (see Wickstead 2008a; 2008b). Helen Wickstead noted that archaeological accounts of field 
drawings still tend to privilege the ends of disciplinary knowledge over the process of engagement. In this case the final conventional drawings - plans and sections - apparently carry more weight than the drawing process itself (Wickstead 2013, 557). Seemingly unproblematic, these formal drawings are actually the prescribed products of applying specific tools, techniques and conventions borrowed from other fields such as technical drawing and map-making (Lucas 2012, 239). The corollary of which is that changing the tool, technique or convention allows different translations of the site to become possible. Extended contemporary art practices, for instance, might help us by providing a counterpoint to the perceived formalisation and systematisation of archaeological practice, allowing some renegotiation of drawing conventions, ultimately generative of new insights for both artist and archaeologist. In practice, field archaeologists already employ, perhaps unconsciously, many other different modes and surfaces of drawing in order to scrutinise the persistent traces and residues they encounter in the course of their investigations. Indeed, in her insightful analysis of the extended nature of drawing within archaeology, Wickstead concluded that

Archaeology is like drawing. Both are arts of the trace, belonging simultaneously to past, present, and future. Drawing is made up of 'betweenesses'. It is both verb and noun, action and the traces of action, presence and absence. It is a reflexive medium that includes and bears witness to its own becoming in the way it writes time.

Drawing is also a performative medium. The becoming of drawing remains evident in the gestural traces it presents. Drawing can make the traces of its becoming available through a process of re-enactment that can be performed in different ways through different viewings. Embracing reflexivity and performativity, drawing exhibits those qualities that are central to archaeologies of the contemporary world (Wickstead 2013, 560).

Wickstead's analysis resonates well with the experience of the present authors.

Both computer-generated and hand-crafted drawings are produced by the team of archaeologists investigating the Moel-y-Gaer hillfort. The many detailed topographic, photogrammetric, remote-sensing, and geophysical surveys are rendered into cartographic manifestations and 3D visualisations using standard, industry available algorithms and instrumentation. In other words they are products of automated cognitive processes, embedded within cognitive artefacts, sometimes disparaged as black-boxes, such as GPS, GPRS, magnetometers, and total stations (see Huggett 2017). Nevertheless, these maps have been invaluable for informing strategic decisions on where to target deeper investigations. In sharp contrast to such industrialised archaeological processes of drawing, but at least important, are the traditional low-tech, slower, hand-measured and hand-drawn works that require discussion and concentration before a single line is committed to record. Here, the usual jigs of gridded pegs, tapes, planning frames and offsets are deployed to help generate standard scale plans (1:20) and sections (1:10), conventionally drawn, with sharp hard pencils (preferably $6 \mathrm{H}$ ) on permatrace secured to gridded drawing boards. The measured drawings depict stylised archaeological contexts (e.g., cuts, interfaces, fills, spreads, layers, lenses, and upstanding remains), which are annotated with their unique single context identifiers. They also feature datum points and lines to enable the records to be tied into the Ordnance Survey geo-referencing framework with great precision using GPS technology. Additional metadata are also recorded on the sheets (e.g. name of recorder, date, drawing catalogue number, title, etc). 
Each catalogued excavation drawing, that is any drawings destined to be part of the archive and perhaps used in publication, is often the second or third expression of the features of interest. More often than not archaeologists rehearse the drawing gestures, at a scale of 1:1, by scoring the interfaces of contiguous contexts or features on the actual surface of the archaeology, using a trowel (see also Flannery 1982; Goodwin 1994; Lemke 1997). We often draw the features of interest for visitors to the site using a $2 \mathrm{~m}$ ranging rod as a stylus, tracing their outlines on the surface of the archaeology. Sometimes, usually in connection with the unravelling of some stratigraphic conundrum, we might also free-hand sketch the trench sections on an A4 sheet of paper. Such small-scale, looser drawing allows us to jointly focus our attention on the pertinent features of problematic stratigraphy, and are easier to handle than the measured profiles rendered across several sheets of $A 3$ permatrace taped together, which flap uncontrollably in the wind. Extremely high resolution orthographic digital photographic montages are also taken and afford automated feature extraction. While these are valuable records in their own right, they are not a substitute for those invaluable sessions in the trench when archaeologists discuss, touch, mark and intellectually dissect the surface of the archaeology in material form before them. Typically, the stratigraphical sequence will also be re-evaluated during this exercise and translated into a fresh freehand drawn Harris Matrix diagram in order to help us unravel the critical paths of temporal succession within the layers and features (Harris 1989). In short, our archaeological drawing practices are iterative and reflexive, and involve both representation and non-representation.

As we have already indicated, the project also fosters an environment of experiential creativity and innovation, hence the development of cutting edge remote-sensing and digitisation technologies. To this end the core team also includes two artists-in-residence: Stefan Gant and Simon Callery. Gant's practice tests and explores the boundaries of contemporary drawing influenced by digital and temporal mediums, whilst Callery's practice resides within the subject and expanded field of painting. For Gant, the residency provides a unique opportunity to re-examine his relationship with his locality, community, landscape and heritage through the discourse of drawing or mark-making.

Gant's first experience of the excavation site was not as you might expect through a visual encounter but instead through the orchestrated sounds of archaeologists scraping. For a practicing artist, the texture of these noises was reminiscent of being in a life drawing class. Gant realised a profound new mode of translation, and of thinking through mark and sound. Here, drawing was presented as a communal and collective engagement. The process of excavation was realised as drawing in a collaborative context. Although discrete spaces, the experience highlighted many shared associations between the life-room and trench, thus becoming a hybrid drawing experience. Moel-y-Gaer was no longer a hill but was transformed into a surface or support for drawing; a surface to receive marks and delineation as an extension of paper, or permatrace, interrogating drawing directly through the land itself. It became a place to learn something new about drawing beyond normative, conventional processes and activate new approaches for describing a place, site and space extending beyond the visual image. Pencil was exchanged for a trowel; the hands of the archaeologists and their practices appropriated by an artist.

Archaeological and artistic accounts of how and what we encounter in the shared space of the Moel-y-Gaer Hillfort at Bodfari have much in common. On the one hand, and pertinent to 
both, is a shared interest in the recording of measurements to make concrete an idea through analysis as straightforwardly as possible, something Stephen Farthing describes as being 'economic... to evidence a rational truth'. On the other hand there is expressive drawing, 'loose [and] spendthrift, having an emotional authenticity made evident by the artist's hand' (Farthing 2005, 25). We would go further and place such rational truth and emotional authenticity in the hands of archaeological excavators.

Continuity and change are the constantly entwined threads of our conversations about our practices of mark-making. They come to the fore as we search to find, and record, our way into, through and out of one stratigraphic context into another. Along the way, colour, texture, acoustic qualities, olfactory characteristics or even the taste of airborne particles might become objects of joint attention. By way of example, Gant recommends the phenomenological approach of 'sniffing your sketchbook' as an effective stimulus to recall and inform memories, since the paper is imbued with the scent as well as the marks of the place. Similarly, the perceptive excavator can often detect subtle smell differences indicating some change of composition within the site's stratigraphy. Even patterns within the interlaced sounds of activity on-site can become objects of joint attention. The steady percussive thuds of the mattock dislodging lumps of topsoil are replaced by the silky rasping scrapes of a trowel on silty turf horizons, or the crunching and rattling cacophony of broken stones being dragged together. Subsequent explosions occur as the spoil hits a wheelbarrow. The sounds of archaeology generated through surface contact share parallels with early lithophones and stone xylophones such as those at the Ruskin Museum in Coniston commissioned by John Ruskin from William Till of Keswick (1840), and earlier the Cumbrian lithophones created by Peter Crosthwaite (1785). We will return to develop this realisation that we can tune into discrete archaeological sounds and draw meaning from them.

Drawing theorist, Philip Rawson, observes that 'drawings basic ingredients are strokes or marks which have a symbolic relationship with experience' (Rawson 1969, 1). He stresses that drawing is an embodied and existential practice, something that we would argue is very akin to the archaeologist's experience of trowelling surfaces. Moreover, by attempting to read a mark it becomes pertinent to the viewer who must now 'create their own mode of truth' (Rawson 1969, 1). Finding a truth appears significant to both contemporary drawing artist and archaeologist, by which we mean to demystify and make sense of our respective subjects.

The language used within our disciplines have many shared and discrete features. For both, the verb to draw asserts the primacy of action and a latent, shared, meaning. The word drawing can be traced back to the Nordic and Old English word dragan, meaning to drag, a primitive and basic action to generate a mark onto a surface. Immediately, the vocabulary of our respective disciplinary dialects begins to offer elements of transferability and thereby opportunities to both reflect and refract.

Associated mark-making terms, grammar and syntax reinforce the observation that the actions and gestures of trowelling and drawing display many affinities. For example, consider the following synonyms for drawing: drag; pull; to move by force; haul with sustained effort; and tug. Moreover, associated actions offer further parallels, such as chase, chip, delineate, echo, etch, gesture, incise, indent, inscribe, mark, peel, reverberate, 
resonate, scar, scrape, scratch, score, scuff, shade, shadow, smudge, stipple, stroke, sweep, trace and trail. Our verb list recalls Richard Serra's Verb List Compilation: Actions to Relate to Oneself in which he developed a series of artworks in line with associated verbs (Serra, 1967-68). All the aforementioned actions require physical exertion and the author's hand to be initially thrown and project its movement away from the body; to reach out and then retrieve, pull back, or initiate multi-directional movement and create feedback via the mark. The gesture thus affords awareness through touch to inform meaning-making and comprehension. Through tactility and traction and the resistance of the surface there exists immediacy, streaming and feedback. The immediacy is streamed through proprioception and receipt of information through touching a surface is intrinsic to both disciplines.

The repetitious actions of mark-making, gestures or 'linear inflexions'; the straight line; the equal, arc-like curve; the angle-curve; and the unequal, or exponential-type curve' (Rawson $1969,89)$ recognised here carry a voice, an identity, imbued by the person, both artist and archaeologist alike, accentuating individual expression. The discipline of graphology lends substance to the observation that individual identity is embodied in the marks, or the actions made. Emotions are also alluded to, and entwined within every stroke. With the body mediating between mind and exposed surface of the buried archaeological feature or context, emotions and authenticity are presented through the hand and simultaneously witnessed. Each stroke is signed and sealed.

Our search for answers through the associated actions recalls Maslow's hierarchy of needs (1954). Both artist and archaeologists make marks to search and realise meaning throughout the duration of the haptic process concentrated on the areas or spaces in question. The aforementioned vocabulary represents a taxonomy of terms in which an individual word or phrase may have a different value, pertinancy or hierarchy when invoked by archaeologists as compared to artistic usage. This suggests a need for a comparative taxonomy of terminologies. Lexicon aside, our experience is that the archaeologists and artists at Bodfari seem to have intersecting interests and processes. When archaeologist and fine artist assign them shared names our modes of enquiry can begin to interoperate. However, our records of these shared encounters reveal often subtle and occasionally profound differences in our responses to these objects of joint attention and our different ways of knowing their pertinent features.

In the following section we try to tease apart these different ways of knowing pertinent features at Bodfari.

\section{Drawing as a mode of enquiry}

Set within the confines and vistas of an area of outstanding natural beauty, the site of Moel$y$-Gaer offers a host of aesthetic attributes. Peeling back the land within the confines of selected archaeology, the features pertinent to artist Gant are informed in this instance by chance encounter and search for a truth. What the artist could connect with was initially unclear. Searching for, and finding, what you are drawn to is both exciting and unnerving. Gant's practice is imbued with themes of theatricality, narrative, documentary, and shares in modes of mapping through human activity. Rites of passage, transience and artistic enquiry with temporal and liminal spaces or arenas are constants. The trenches and participants at 
Bodfari pooled and synergised these interests. The void of the trench, dematerialised ${ }^{1}$, or disassembled, by hand, itself became an object of interest (figure 1). Trowelling actions were pertinent. Connecting to surface deposits haptically and sonically provided a research catalyst. The flow back in time through material, objects and stratification (or delineation) became significant. How archaeologists draw and represent their findings became equally significant.

Field archaeologists expend much time and effort clearing then probing with their trowels, listening to, feeling, actively looking at, and marking the archaeology. Besides practicing traditional field archaeological methods and techniques, Reilly has investigated the potential of alternative, virtual, digitally creative, archaeologies, exploring the craft aspects of digital archaeological practice (e.g. Reilly 1985; 1991; 1992; 2015a; 2015b; Beale and Reilly $2017 \mathrm{a} ; 2017 \mathrm{~b})$. Both archaeological and artistic ways of knowing are largely tacit and unspoken, until we started conversing. Our shared dialogue concerning the role and application of drawing produced a generative dichotomy when our conversations strayed into the expanded contexts of contemporary drawing, where the purpose and function of representational and more experimental modes of drawing intersect. Pertinent features could now be portrayed and interpreted through a spectrum of conventional and unconventional approaches. Traditional drawing is common to both disciplines, yet contemporary notions of drawing extend through the expanded field of drawing; harnessing modern technologies within the disciplines of both field archaeology and fine art drawing practice.

In both archaeology and fine art, drawing practice today extends beyond traditional notions of tools such as the pencil and the support of paper. Practitioners continue to test the subject's known boundaries. For some such as Gant's former mentor and painter, Peter Prendergast (pers.comm), drawing is ninety percent looking and ten percent doing, the sense of ambiguity created by doing is offset by an equal measure of potential. By contrast, the work of Claude Heath is the antithesis of Prendergast. Heath draws blindfolded, responding to form through proprioception, experiencing or apprehending the world through his hand, fingers and touch (Staff 2015). Field archaeologists can sympathise with both these positions, recognising that they are not mutually exclusive. Reilly, for instance, was early to experiment with handheld 3D digitising devices mounted on a bespoke perspex stylus to record archaeological features, such as the body silhouettes uncovered in the soils of the Anglo-Saxon cemetery of Sutton Hoo in the late 1980s. So-called sandmen were drawn, digitally, in three-dimensions (Reilly and Richards 1988; Reilly, Richards and Walter 1988). Aside from the technology, what was novel here was the ability to draw, and document, without direct lines of sight. Registration of the deceased's persistent form was achieved incrementally as the stylus made contact point after point with the surface of the sandmen. The device enabled the shapes of obscured, or out-of-sight, nooks and crannies to be captured haptically in situations where a laser scanner could not reach. Clearly, haptic enquiries are integral to our respective processes of drawing. Other senses can also be activated: for example, we demonstrate below that sound is also a medium of drawing.

\footnotetext{
${ }^{1}$ For the purposes of this paper the terms dematerialise, materialise and rematerialise refer to archaeological concepts pertaining to how the archaeological record encountered in field through the interventions of excavators produces, or (re)materialises, new entities in another imbricated archaeological record commonly known as the archive (See Lucas 2012 for an in depth discussion).
} 
In a period of unprecedented pace and connectivity drawing slows both artist and archaeologist down and heightens experiential learning when observing an archaeological site. It helps with 'getting your eye in' (Wickstead 2008b, 15), but recognises the value of different perspectives. Deanna Petherbridge (2010) describes drawing as a multipractice manifesting drawings in an age of pluralism. Drawing invites probity, interrogation, speculation and enquiry, initiating recording into vistas of visual and non visual arenas, events, activities and actions through associated drawing tools that extend into temporal lens-based mediums. In relation to the process of drawing and mark-making, Emma Cocker asserts that:

Each line is performed as an unknowing, an unmeaning, the ritual reversal of habitual ways of thinking, the gesture of (making a) clearing. Here, clearing does not produce clarity, but simply gives permission for another kind of thinking and knowing without prescribing what is allowed: it simply makes possible (Cocker 2012, xiii).

This insight resonates with artist and archaeologist alike being equally pertinent to the questing actions of both trowelling and drawing (e.g. Edgeworth 2013), and therein lies a measure of their transferability across, and interoperability between, our disciplinary modes of expression.

Scopic discourse, of course, is just one mode of interaction and our dialogue with the site is not constrained to the visual. Drawing at Bodfari is embodied analysis in which contexts are actively looked at, touched, heard and acknowledged, and thus haptic, sonic and cross modal dialogues also emerge through our mark-making practices. Chance encounters, play, and exploration of landscape, site, space and surface are exercised through interdependent experiential dialogues with mark-making enriched by the introduction of a plethora of technologies formerly unknown for recording and mapping. Contemporary drawing notions embrace these tools and processes, revealing and releasing new perspectives. Sketchbooks extend beyond the confines of their support into external hard drives, whilst drawing tools translate the pencil to microphones, and are further extended by the drag and mark of trowels, mattocks and shovels.

In both practices, the marks and physical memories of artist and archaeologist alike emerge, intra-actively (see Barad, 2007) through the objects of study. The tools of exploration and the practitioners are enmeshed in the activities including: remote sensing, surveying, mattocking, trowelling, drawing, photographing, videoing and sound recording (Reilly and Beale 2017a). In our universe, marks represent the co-signatures of the often anonymous practitioners (Everill 2009), the voice of the deposits, as well as the imprint of the tools, and their interplay creates a multi-threaded narrative documenting their modes of interaction, in short our practices. They therefore occupy the conceptual space of paradata, and in the process of saturating the interstices of cognitive artefacts or prosthetics, that is our quotidian apparatus of observation and recording, they lend probity to their translations into both art form and archive.

The importance of paradata, otherwise termed provenance metadata (Mudge 2012), amongst the digital archaeologists and the virtual heritage community has been in the ascent over recent years (e.g., Bentkowska-Kafel, Baker, and Denard 2012; Mudge 2012; Damnjanovic, Hermon and lannone 2013; Huggett 2014). Paradata document the intellectual and methodological processes by which, and circumstances under which, data or interpretations have been arrived at. It is closely linked to metadata which convey 
information concerning what the data are intended to represent. The importance of both metadata and, subsequently, paradata stems from a long-standing anxiety within the disciplines of virtual archaeology and virtual heritage about how to convey the authenticity of the models, the authority of their creators, and the quality of the data they are based on. The difficulty with the approach is that although paradata are intended to lend greater authority and authenticity to the data and metadata, the provenance of the paradata themselves is not unproblematic. Each time we try to step back as it were and take stock of what we are doing we add another layer of evaluation or introspection, potentially an infinite regression. We name these latest nested datasets of introspection, pertaining to why the recorded paradata data were selected as most pertinent, peridata. Who decides what these ever expanding peripheral, but inward-looking, processes of surveillance and control should be, and how they should be monitored, recorded and conveyed, and by whom or what is a discussion for elsewhere.

For now, we would argue that through their entangled interactions the tools, deposits, and diggers mutually constitute paradata and thereby become advocates (Huvila 2009) of one another. In other words, they mark each other unselfconsciously with auto-archived paradata; they are not consciously selected remarks but the byproduct of embodied action. Without resorting to the language of surveillance and control, traces of actions are realised spontaneously, both physically and psychologically.

Tim Ingold, following Ferdinand de Saussure, suggests that sounds 'imprint on the surface of the mind' (Ingold 2007, 7-8). The sounds bouncing off surfaces leave acoustic marks on one's imagination. The build-up of sounds creates or triggers visualisation, informs decisions, ideas, knowledge and forms over time. The material removed, deconstructed, dematerialised - mentally and physically processed - are rematerialised as mounds. Spoil heaps are the shattered remnants of decisions and thinking. Striations of the trowelling process also reveal aspects of this processing on the excavated material when peeling back the surface. A working trowel becomes ever more susceptible to examination as it is gradually worn away by myriad scrapes and abrasions (figure 2). The trace of the archaeologist's gestural action is registered like a signature and authorship is assigned to the trowel, which over time is also inscribed, or co-signed, by the very surfaces it disassembled. The trench leaves its imprint on the instrument, imbued through it, just as a pencil is worn down. Similarly, the composition of graphite found in pencils contains clay, earth materials that further plays out this process. Tools and layers also pay homage and testimony to differing dimensions of experience.

The eroding aspect of these tools over time recalls the repetitive act and gesture. Amore $(2003,75)$ explores repetition by citing Howell's (1999, 30-31) response to Deleuze (1968, $15)$ in Difference and Repetition who spoke of 'an inverse relationship between repetition and consciousness, repetition and remembering, repetition and recognition'. Foregrounding repeated actions and its proximity to thought and mental processing can be also be extended into the tools used and areas worn away. Worn away areas highlighted through their absence express notions of object memory. This can be extended to the drawing instruments, here telling the story of their owners, where signatures and surfaces engage symbiotically imbuing the memory of past encounters and connections (figure 2). Marks here are traces unseen and the negative spaces of what once was. The absence of parts of the original tool is a presentation of memory. These marks - for example, trowel marks on the 
deposit, abrasions on the tools, cross-modally bound impressions on the mind and muscles of the digger such as colours, sounds, smells and haptic responses - record in tractable but not necessarily explicit detail how tacitly understood techniques of working were deployed. They bear unemotional witness to those unfurling moments when the mass solipsism of millions of individual questing, scraping gestures and marks (made as the archaeologists subtly probe through tonnes of incoherent shale sherds with their trowels and other tools) gradually coheres into something meaningful. Eventually, some locus of prior activity, perhaps the structured planes of placed slabs, seems to precipitate out. And so the rubble madness dissipates, as the jumble of shale sherds seem to coalesce, enlarge and take form, to materialise out a hypothesis: a revetted rear face to the middle rampart?

\section{Towards an archaeology of gestures and paradata}

Ingold $(2007,4)$ suggests that our thinking processes are externalised through our marks. For instance, 'straightness epitomizes rational thought and disputation'. Thus in tracing the gamut of dextrous movements of the archaeologist's trowelling gestures and rendering them as pencil lines on paper, a new mode and aesthetic of mapping cum analytical drawing is created (figure 3). These visible marks appear fluid and decisive 'moments of completion' (see Ingold 2007, 80). However they record only a partial record of the meshwork of questing trowel strokes, as the totality of the trowel's journey, conducted by archaeologist's hand, is not depicted. Each line presented is a residual trace of only that part of the transit where the trowel, digger and gesture make contact and become entangled as the surface of the exposed archaeology is simultaneously inscribed and erased.

The feathered terminals of these lines in fact flow invisibly from, or into, the unfolding loops of the now frictionless but still questing trowel. In other words the apparent breaks in the meshwork presence those 'moments of tension' (Ingold 2007, 79) when the archaeologist decides subliminally what to expose next. In these evocative, atemporal, arrangements of superimposed marks we begin to discern unconscious intent and improvisations of the field archaeologists when trowelling.

Other modes of translation enable us to capture and deepen insights into the embodied practice of trowelling. For example, temporal dynamics are re-enacted when the marks are expressed as 3D physical instantiations in the form of linear card strips cut to the same length as the trowel traces, orientated correctly, and then stacked each in turn on top of the previous stroke. Here the points of contact between each successive card line or linear inflexion are also paradata, every one referencing an instant of pre-reflexive divination, an Ingoldian 'moment of tension', a 'seemingly inconsequential micro-decision' (Carter 2017), that usually passes unnoticed within the unfolding flow, or ductus, of the moving trowel. The physical objects, or linear inflexion mappings, that Gant develops recall the uncanny lines of confused divination created when a priest spills out qian sticks in Taoist rituals. However, it would seem that we can indeed begin, as Helen Wickstead posited, to excavate the relative stratigraphy of gestures, traces and marks (Wickstead 2013, 561). The radiating sequences among these lines realise a sense of 'deep notional space' (Rawson 1969, 131) which is of great significance, demanding to be explored. At times these offer examples such as: staggered, offset, closely spaced, far apart, in unison, parallel alignment or random distribution on multiple contours. Each pattern is distinct to the owner and can be attributed to their level of experience and ability to tune in to the surface. This is akin to amateur as 
opposed to professional draftsman, or distinctions between artistic approaches, such as between, for example, Rembrandt or Cezanne. The gamut examines the set of directions used within a drawing connecting shared meaning between both artist and archaeologist. Rawson contends that the 'existence of an overall gamut, wide or small, is one of the strongest means for relating disparate parts and separate linear inventions within the spread of a drawing' (Rawson 1969, 132). The spread of these marks from the mediating hand, anchored by the body, project and radiate out from the front of the body. The inter-related position of the body to the mark is significant and offers extended or shared terminologies.

Figure 4 shows a single view from an interactive reflectance transformation image (RTI). In this collaborative work our complimentary archaeological and artistic modes of expression are fully intertwined. Linear Phrasing RTI is derived from one of Gant's earlier pieces expressed in card stripes and entitled Linear Phrasing, 2016. Linear Phrasing RTI is another investigation into plasticity or 3D volume drawn out in a gamut of Reilly's trowelling gestures. Here, in an ontological twist, the earlier physical artwork, in which dematerialised strokes of archaeology were rematerialised in card, is now dematerialised into a virtual object, which is then re-expressed, after applying specular rendering that recalls graphite, using an archaeological form of computational photography. Our objects of joint attention are now (im)material and susceptible to transmutations within a phygital nexus, a no-place and an everyplace where objects may flicker in and out of physical and digital universes.

RTI was originally developed from the technique of polynomial texture mapping by the archaeological and heritage communities as a vehicle to record, represent and analyse artefacts (see Cultural Heritage Imaging), and it has been applied widely (e.g., Beale and Reilly 2017a; 2017b). In essence, RTI captures an object's surface, shape and colour, and enables virtual interactive re-lighting of the captured surfaces from any direction to afford new and extremely intimate engagements with archaeological material. In Linear Phrasing $R T I$ this latest mode of translation enables us to capture and deepen insights concerning the relative stratigraphy of our archaeological gestures, traces, and marks - our embodied practices - by emancipating aesthetic paradata as art work.

\section{Rhythmic Dematerialisation or Sounding out the Stratigraphy}

Resonant sound has long been appreciated as an investigative medium by both artists and archaeologists. We have already mentioned the artist Ruskin, and archaeologists can point to sophisticated side-scanning sonar applied in marine archaeological contexts. However, much more primitive acoustic sensors have been available to archaeologists and earlier antiquarians for centuries. Everyday hand tools afford the technique of bosing (or bowsing). By thumping the ground with the head of a pick or mattock (sometimes even a trowel) field workers are able to crudely locate and define the edges of buried archaeological features such as ditches, walls and voids based on the distinctive resonant sounds that are returned from, for instance, compacted, loose, hollow and undisturbed earth.

Unsurprisingly then, the archaeological indicator of sound is another medium of drawing being explored at the Moel-y-Gaer, Bodfari excavations. The artwork Sonic Stratigraphy (Sub Soil) Gant, S. (2014-16) is derived through audio visualisation software and explores 
acoustic signatures within the excavation realised and activated through contact with a trowel stroke and an archaeologically-defined surface (figure 5).

The interfaces between layers are recognised by changes in tone, frequency, and both together. Associated prominent frequency ranges are displayed by darker tones along the vertical axis emphasising strengths of frequencies. The patterns that emerge in this extended drawing appear as repetitive marks that recall the excavators' rhythmical encounter with surface. The graded tonal ranges across the image represent subtle and prominent frequencies, measuring amplitude levels in decibels relative to full scale (dBFS). Rhythmicity, cadence, and gestures are acknowledged and become signatures of the excavators (collectively or individually, depending on the particular recording). The drag actions become expressive through tone and vertical delineation. The horizontal axis depicts time. Notions of surface and context timbres are distilled through this process, and are imbued by the tactile intimacy of this conversation with ancient ground.

Another artwork, Sonic Stratigraphy Series S, Gant. (2014-2016) presents an interrogation of mark-making using hand tools over time; from the mattocked archaeological surfaces all the way through trowelled deposits to the natural deposits uncovered in the base of the trench. This contemporary drawing reveals, and embodies sonically, existential experience of a specific space haptically engaged, in this instance through sound. The piece also references what Rawson $(1969,95)$ refers to as the importance of 'linear phrasing' of marks; springing from one to the next and so on. Sonic stratigraphy explores mapping in a non-cartesian way, building an enquiry into our relationships with surfaces physically, and depicts an approach which expands from a two-dimensional linear enquiry into three-dimensional volumetrics, known as 'plasticity' (Rawson 1969, 94), the enquiry of depth. Relationships between a scrape or stroke as one leads to another is perceived as 'a demand of good drawing' according to Rawson $(1969,91)$. The dichotomy and polarity of dematerialisation of surface, working backwards, and rematerialisation through art practice has released new approaches for personal consideration in regard to drawing practices. The dematerialisation of an object is rematerialised here through the artwork, producing associated textures and tones through graphic constructs whilst making physical the immediacy and externalised thoughts of the maker.

Synergising these various surfaces of layers within the ground in an artwork finds parity with the progressive and temporal nature of traditional drawing and mark-making, exploring the built nature, structure and constructs on two dimensional surfaces when drawing. Every drawing, through lines or marks, records and reveals the order of routes of thought through visual and non-visual enquiry. There is a long history of thinking through touch, mark-making or line built into the sensory creation of a drawing. Ingold (2007), enriches this idea by suggesting that knowledge is born of movement, from having confidence. Excavators engage with archaeological surfaces in a very similar way as the engaged artists draws, that is through rhythmical mark-making. Whereas artists might develop an enquiry by building up marks on a support, the actions of the archaeologist create a lively, ongoing, palimpsest; each mark of the excavator's tool is simultaneously an erasure and an inscription, producing a series of continuously reducing archaeological surfaces. However, archaeological layers have depth and volume as well as surfaces and are frequently not materially homogeneous. Indeed layers often encapsulate many subtle changes recalling formation processes and uneven passages of time which can be visually indistinguishable, but are detectable 
haptically and acoustically. Archaeological gestures probe and interrogate interstitial spaces, and with each stroke a new surface is revealed, and every new surface has the potential to reveal another register of material properties and sensorial feedback. Each gesture leaves a waymark. In both artistic and archaeological cases, there is a shared probity, the rhythm and the action create a connection through mêtis via the surface; the sounds rise up and bond with the owner. Cocker (2012, xvi), quoting Marcel Detienne and Jean-Pierre Vernant (1991, 3-4), captures the concept of mêtis as:

a mode of time characterized by opportunism, a "type of intelligence and of thought; a way of knowing; it implies a complex but very coherent body of mental attitudes and intellectual behaviours which combine flair, wisdom, forethought, subtlety of mind, deception, resourcefulness, vigilance, opportunism... it is applied to situations which are transient, shifting, disconcerting, and ambiguous, situations which do not lend themselves to precise measurement, exact calculation or rigorous logic".

Manual rhythms and gestures (lines) assist in revealing a form of knowledge production or tactile knowledge construction by the author in association with the material and the tool, something artist Claude Heath describes as 'drawing being able to tell a story through itself, by itself' (Gunning et al. 2003, 24). Both Sonic Stratigraphy (Sub Soil) and Sonic Stratigraphy (Series S) testify to this.

\section{Conclusion}

The theoretical underpinning of traditional drawing practice give prominence to the crossmodal actions of the archaeological excavator. Our artistic and archaeological collaboration at the Moel-y-Gaer, Bodfari investigations demonstrate a parity between drawer and archaeological field excavator, while recognising variants from novice to professional. It has become apparent that we share melodic rhythms and gestures as a common vocabulary, inflecting them, breaking them, and causing them to spring one from another with linear phrasing. Our modes of mark-making reflect very skilled exploration and exposition techniques, and realise a highly sophisticated mode of meaning-making.

We have demonstrated that drawing theory foregrounds signatures and authorship: thinking through mark-making. In so doing, we discovered an alternative to the language of surveillance and control, one which gives voice to the diggers, tools, and deposits, each marked by the other and thus attesting for the others' being. The traces left by the metis and ductus of mark-making subtly, but now inexorably, draw our attention to our processes of thinking and decision making revealed in gestures, our modes of expression. Auto-archived, and advocates of the excavators, the archaeology, and the tools, marks may be reconceptualised as both fine art, paradata, and the waymarks of field archaeology.

Our conversation reflects a genuine collaboration, involving transformative exchange and contributions from one discipline to the other. We would argue that this rich bilateral exchange has expanded both our practices; realising many shared vocabularies and, moreover, offering new vocabularies as descriptors that could be applied to both of our specialist disciplines. 
We started out with the word draw, a verb and a noun whose root is dragan, meaning to drag. An exploration of its many connotations enabled us to establish an agreed transferable and descriptive exchange between artist and field archaeologist, reciprocating excavation actions, surface interrogations and exploration. The sounds of excavation teams found parity with the resonant pencil sounds in a life drawing class, a form of communal art process and an artistic event at the ancient space on Moel-y-Gaer, Bodfari. Both processes elicit gestural action, agency and surface enquiry. The sounds generated through touching a surface acted as a catalyst to extend the artist's notions of drawing practice. The actions of the excavator transmuted within the 'expanded field' of contemporary drawing practice. The resulting artwork was in turn transferable to an archaeologist who recognised it as a non-cartesian method and approach to mapping not just surfaces but also the plasticity of volumetrics, moving beyond and laterally from established practices of the field archaeologist. This was one of our most striking shared insights.

The word palimpsest, connoting simultaneous erasure and inscription, is also a significant extension to drawing terminology for artists realised through this dialogue with archaeologists during this project. Here too the vocabulary and concepts of archaeology are transferable to drawing and possibly other fine art disciplines that share associated processes.

Finally, the concept of paradata presented by an archaeologist is also significant when aligned to the traditional material conventions of drawing. Paradata employ a measure of immaterial, whilst drawing is arguably commonly understood as material based practice. The progression of drawing within the expanded field, in a post digital age, has seen shifts towards drawing being expressed as dematerialised work in a digital context before being returned to paper through printing processes. This in turn brings into question measures of human agency, particularly during a period that has given rise to the term 'post-human'.

During our conversations we have wandered constantly between material and immaterial worlds, often flipping between the two, resulting in a body of transmuted outputs that ultimately present a fusion. This in turn challenges notions of a drawing when translated through digital binary code into bits, largely made possible through the notion of drawing within an expanded field.

Importantly, the dialogue here is between a practicing artist and archaeologist who have both been immersed in, and embraced, the rapid influx of digital technology and creativity that has defined their respective practices. The neologism phygital (simultaneously physical and digital), provides a valuable mechanism for uncovering or disclosing what had been happening in drawings that span the (im)material and embody a measure of (de)humanisation. The concept of phygital should be welcomed within the context of contemporary drawing at a time when the impact of the digital on drawing practice still lacks critical appraisal and associated major exhibitions. In this instance, the term extends our vocabulary and now foregrounds the progression of our associated disciplines, cross modal methods and approaches.

In summary, our embodied analysis of the rhythmic and linear phrasing of dematerialisation and rematerialisation brings the act and art of archaeology to the forefront and extends the multi-platform approaches and challenges that contemporary drawing activity can embrace. 
A primary value of drawing is inquisition and enquiry. Although the final record is mandatory, the routes to, and formats of, this objective can be many and varied. The site and collaboration at Moel-y-Gaer, Bodfari, has activated a test bed for sharing practices and explorations of what contemporary drawing and archaeological mark-making can be. To this end, drawing for the artist and archaeologist will continue to be framed and realised within the context of this unique site and associated collaborators.

\section{References}

Abdulla, B.O., Anstis, S., Arnell, M., Barron, R. et al. 2016. Can You Dig it? What happens when ten artists engage with archaeological practices. Gothenburg: University of Gothenburg.

Amore, I. 2003. 'Lucy Gunning: Wearing flowers, drawing flowers, looking at flowers'. In: Gunner et al. (eds), What is drawing? three practices explored: Lucy Gunning, Claude Heath, Rae Smith. London: Black Dog Publishing.

Barad, K. 2007. Meeting the Universe Halfway: Quantum Physics and the Entanglements of Matter and Meaning. London: Duke University Press.

Beale, G., Beale, N., Minkin, L. and Dawson, I. 2013. 'Making digital: visual approaches to the digital humanities'. In: Ng, K., McDaid, S. and Bowen, J. (eds) EVA London 2013: Electronic Visualisation and the Arts. Proceedings of a conference held in London 29-31 July, London: BCS, The Chartered Institute for IT. 240-55.

Beale, G. and Reilly, P. 2017a. 'Digital Practice as Meaning Making in Archaeology', Internet Archaeology, 44. https://doi.org/10.11141/ia.44.13

Beale, G. and Reilly, P. 2017b. 'After Virtual Archaeology: Rethinking Archaeological Approaches to the Adoption of Digital Technology', Internet Archaeology, 44.

https://doi.org/10.11141/ia.44.1

Bentkowska-Kafel, A., Baker, A. and Dendard, H. (eds) 2012. Paradata and Transparency in Virtual Heritage, Digital Research in the Arts and Humanities Series. Farnham: Ashgate.

Biggs, J. B. 1985. 'The role of meta-learning in study processes', British Journal of Educational Psychology, 55, 185-212. DOI: 10.1111/j.2044-8279.1985.tb02625.x

Birgerstam, P. 2002. 'Intuition--the Way to Meaningful Knowledge', Studies in Higher Education, 27(4), 431-444. DOI: 10.1080/0307507022000011543

Carter, M. 2017. 'Getting to the Point: Making, Wayfaring, Loss and Memory as MeaningMaking in Virtual Archaeology', Virtual Archaeology Review, 8(16). http://dx.doi.org/10.4995/var.2017.6056

Chittock, C and Valdez-Tullett, J (eds) 2017. Archaeology With Art. Oxford: Archaeopress. 
Cocker, E. 2012 'The Restless Line, Drawing'. In: Sawdon, P. and Marshall, R. (eds) Hyperdrawing: Beyond the Lines of Contemporary Art. I.B.Tauris, xii-xvi.

Crawford, M. 2015. The World Beyond Your Head: How to Flourish in an Age of Distraction. London: Penguin.

Damnjanovic, U., Hermon,S. and lannone,G. 2013."Documentation of the decision-making process in the analysis of digital heritage objects," 2013 Digital Heritage International Congress (DigitalHeritage), Marseille, 2013, 743-746. DOI:

10.1109/DigitalHeritage.2013.6743831

Deacon, R. 2014. Abstract Drawing. London: Riding House.

Deleuze, G. 1968.Difference and Repetition, Translated by P. Patton. Presses Universitaires de France.

Denard, H. 2012. 'A New Introduction to the London Charter', in Bentkowska-Kafel, A., Baker, A. and Dendard, H. (eds), Paradata and Transparency in Virtual Heritage, Digital Research in the Arts and Humanities Series. Farnham: Ashgate, 57-71.

Detienne, M. and Vernant, J-P. 1991. Cunning Intelligence in Greek Culture and Society, translated by Janet LLoyd. Chicago: University of Chicago Press.

Edgeworth, M. 2013. 'The Clearing: archaeology and ways of opening the world'. In: González-Ruibal, A. (Ed.), Reclaiming Archaeology: Beyond the Tropes of Modernity. Abingdon: Routledge, 33-43.

Everill, P. 2009. The Invisible Diggers: A Study of British Commercial Archaeology, 2nd Revised Edition. Oxford: Oxbow Books.

Farthing, S. 2005. Dirtying the Paper Delicately. London: Furnival Press.

Ferraby, R. 2017. 'Geophysics: creativity and the archaeological imagination', Internet Archaeology, 44. https://doi.org/10.11141/ia.44.4

Flannery, K.V. 1992. 'The Golden Marshalltown: A Parable for the Archeology of the 1980s', American Anthropologist, New Series, 84(3), 265-278.

González-Ruibal, A. (Ed.) 2013. Reclaiming Archaeology: Beyond the Tropes of Modernity. Abingdon: Routledge.

Goodwin, C. 1994. 'Professional Vision', American Anthropologist, 96(3), 606-633.

Graves-Brown, P. 2013. 'Inside is out: an epistemology of surfaces and substances' in: González-Ruibal, A. (Ed.), Reclaiming Archaeology: Beyond the Tropes of Modernity. Abingdon: Routledge, 298-310. 
Gunning, L., Kingston, A., Heath, C. and Smith, R, 2003. What is drawing?: three practices explored: Lucy Gunning, Claude Heath, Rae Smith. London: Black Dog Publishing.

Harris, E.C. 1989. Principles of Archaeological Stratigraphy, 2nd Edition. London: Academic Press.

Howell, A. 1999. The Analysis of Performance Art. Amsterdam: Harwood Academic Publishers.

Huggett, J. 2014. Promise and Paradox: Accessing Open Data in Archaeology. In: Mills, C., Pidd, M. and Ward (eds), Proceedings of the Digital Humanities Congress 2012. Studies in the Digital Humanities. Sheffield: HRI Online Publications. Available online at: https://www.hrionline.ac.uk/openbook/chapter/dhc2012-huggett

Huggett, J. 2017. 'The Apparatus of Digital Archaeology', Internet Archaeology, 44. https://doi.org/10.11141/ia.44.7

Huvila, I. 2009. 'My Stratigraphy, Your Stratigraphy? Stratigraphic Documentation as Record and Information', Suomen Keskiajan Arkeologian Seuran (SKAS), 4, 15-21.

Ingold, T. 2007. Lines, a Brief History. Abingdon: Routledge.

Laing, R.D., Phillipson, H. and Lee, A.R. 1966. Interpersonal Perception: A Theory and a Method of Research. London: Tavistock Publications.

Lemke, M. 1997. 'Give me WHS or give me death!' Assemblage, 2 (2nd May 1997).

Available:

https://archaeologydataservice.ac.uk/archives/view/assemblage/html/2/2trowel2.html (Last accessed 17th May 2017).

Lock, G. and Pouncett, J. 2012. 'Moel-Y-Gaer Hillfort, Bodfari, Denbighshire, SJ 0950 7080', Archaeoleg yng Nghymru, Archaeology in Wales, 51, 142-45.

Lock, G. and Pouncett, J. 2014. Excavation in 2012 and 2013 at Moel y Gaer, Bodfari, Denbighshire, SJ 095 708. Archaeoleg yng Nghymru, Archaeology in Wales, 53, 83-97.

Lucas, G. 2012. Understanding the Archaeological Record, Cambridge: CUP.

Maslow, A. 1954. Motivation and Personality (1st edition). New York: Harper.

Mudge, M. 20102. Transparency for empirical data'. In: Bentkowska-Kafel, A., Baker, A. and Dendard, H. (eds) 2012. Paradata and Transparency in Virtual Heritage, Digital Research in the Arts and Humanities Series. Farnham: Ashgate, 177-188.

Petherbridge, D. 2010. The Primacy of Drawing: Histories and Theories of Practice. London: Yale University Press. 
Rawson, P. 1969. Drawing. Oxford: Oxford University Press.

Reilly, P. 1985. 'Computers in field archaeology: agents of change?' in M.A. Cooper and J.D. Richards (eds) Current Issues in Archaeological Computing, British Archaeological Reports International Series 271. Oxford: BAR. 63-78.

Reilly, P. 1991. 'Towards a virtual archaeology' in S. Rahtz, and K. Lockyear (eds) CAA90. Computer Applications and Quantitative Methods in Archaeology 1990, British

Archaeological Reports International Series 565. Oxford: Tempus Reparatum, 132-39.

Reilly, P. 1992. 'Three-dimensional modelling and primary archaeological data' in P. Reilly and S. Rahtz (eds) Archaeology in the Information Age: a global perspective, London: Routledge, 145-73.

Reilly, P. 2015a. 'Palimpsests of immaterial assemblages taken out of context: tracing Pompeians from the void into the digital', Norwegian Archaeological Review, 48(2), 89-104. https://doi.org/10.1080/00293652.2015.1086812

Reilly, P. 2015b. 'Additive Archaeology: An Alternative Framework for Recontextualising Archaeological Entities', Open Archaeology, 1, 225-235. DOI:10.1515/opar-2015-0013

Reilly, P. and Richards, J. 1988. 'New Perspectives at Sutton Hoo: the potential of 3-D graphics', Bulletin of the Sutton Hoo Research Committee, 5, 24-27.

Reilly, P., Richards, J.D. and Walter, A. 1988. 'Graphics at Sutton Hoo: the potential of 3-D graphics', in Ruggles, C.L.N. and S.P.Q. Rahtz (eds.), CAA87. Computer and Quantitative Methods in Archaeology 1987, BAR International Series 393. Oxford: BAR, pp. 171-185.

Renfrew, C. 200. Figuring it out: What are we? Where do we come from? The parallel visions of artists and archaeologists. London: Thames and Hudson.

Renfrew, C., Gosden, C., DeMarrias, E., 2004. Substance, Memory and Display: archaeology and art. Cambridge: McDonald Monograph Series.

Russell, I. and Cochrane, A. (eds) 2014. Art and Archaeology: Collaborations, Conversations: Criticism. New York: Springer.

Smith, C. 2017. 'Beyond metaphor: archaeology as a social and artistic practice', Journal of Visual Art Practice, 15(2-3), 270-285.

Staff, C. 2015. 'Burrowing under the apparent: the blindfold drawings of Claude Heath'. In: Guerin, F. (Ed.) On Not Looking: The Paradox of Contemporary Visual Culture. New York: Routledge, 123-138.

Stapleton, P. 1909. 'Exploration of Moel-y-Gaer, Bodfari'. Archaeologia Cambrensis, 6th series, IX, 232-238. 
Wendrich, W. (Ed.) 2012. Archaeology and Apprenticeship: Body Knowledge, Identity, and Communities of Practice. University of Arizona Press.

Wickstead, H. 2008a. 'Drawing time', British Archaeology, 101, 44-49.

Wickstead, H. 2008b. 'Drawing archaeology'. In: Duff, L., and Sawdon, P. (eds.) Drawing: the purpose. Bristol: Intellect Books, 13-27.

Wickstead, H. 2013. 'Between the lines: drawing archaeology'. In: Graves-Brown, P., Harrison, R. and Piccini, A. (eds.), The Oxford Handbook of the Archaeology of the Contemporary World. Oxford: Oxford University Press, 549-564. 